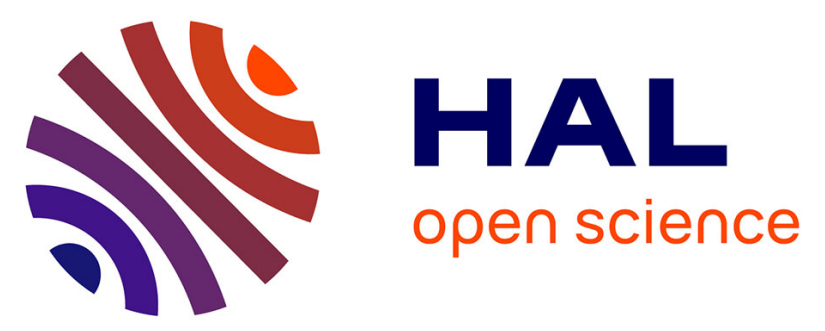

\title{
Predicting the flame characteristics and rate of spread in fires propagating in a bed of Pinus pinaster using Artificial Neural Networks
}

Khaled Chetehouna, Eddy El Tabach, Loubna Bouazaoui, Nicolas Gascoin

\section{- To cite this version:}

Khaled Chetehouna, Eddy El Tabach, Loubna Bouazaoui, Nicolas Gascoin. Predicting the flame characteristics and rate of spread in fires propagating in a bed of Pinus pinaster using Artificial Neural Networks. Process Safety and Environmental Protection, 2015, 98, pp.50-56. 10.1016/j.psep.2015.06.010 . hal-01253272

\section{HAL Id: hal-01253272 \\ https://hal.science/hal-01253272}

Submitted on 19 Feb 2016

HAL is a multi-disciplinary open access archive for the deposit and dissemination of scientific research documents, whether they are published or not. The documents may come from teaching and research institutions in France or abroad, or from public or private research centers.
L'archive ouverte pluridisciplinaire HAL, est destinée au dépôt et à la diffusion de documents scientifiques de niveau recherche, publiés ou non, émanant des établissements d'enseignement et de recherche français ou étrangers, des laboratoires publics ou privés. 


\title{
Predicting the flame characteristics and rate of spread in fires
}

\section{propagating in a bed of Pinus pinaster using Artificial Neural}

\section{Networks}

\author{
Khaled Chetehouna ${ }^{1, *}$, Eddy El Tabach ${ }^{2}$, Loubna Bouazaoui ${ }^{2}$, Nicolas Gascoin ${ }^{1}$ \\ ${ }^{1}$ INSA Centre Val de Loire, University of Orléans, PRISME EA 4229, 88 Boulevard \\ Lahitolle, 18000 Bourges, France. \\ ${ }^{2}$ IUT of Bourges, PRISME laboratory, University of Orléans, 63 avenue de Lattre de \\ Tassigny, 18020 Bourges Cedex, France. \\ * Corresponding author. E-mail adress: khaled.chetehouna@insa-cvl.fr; Tel.: +33 2 \\ 48484065
}

\begin{abstract}
Physical and geometrical characteristics of flame propagation are very important to better understand the forest fire spread behaviour and to improve risk management tools. Having a tool to predict these characteristics is of practical and theoretical interest for a better understanding of the complex chemical and physical mechanisms which occur during forest fire phenomena. A metamodel is presented based on Artificial Neural Networks (ANNs) for estimating physical and geometrical parameters of the forest fire front, namely the rate of spread $(R O S)$, flame height $\left(H_{f}\right)$ and flame tilt angle $\left(\alpha_{\mathrm{f}}\right)$. The ANN was developed using literature data obtained from experiments of fire propagation in beds of Pinus pinaster needles. The optimal feedforward ANN architecture with error backpropagation (BPNN) was determined by the cross validation method. The ANN architecture having 5 hidden neurons
\end{abstract}


proved to be the best choice. Comparing the modelled values by the ANN with the experimental data indicates that neural network model provide accurate results. The performance of the ANN model was compared with a metamodelling method using a multilinear regression approximation.

KEYWORDS: Forest fires, Rate of spread, Flame geometrical characteristics, Simulation metamodelling, Artificial neural networks, Backpropagation. 


\section{Introduction}

Forest fires have always existed and nowadays, due to climate changes, they are becoming a growing threat for human life and ecosystems in the world. Every year, the average areas of forest destroyed by fire in the world and in Europe are about 28 and 1.6 million hectares respectively. Moreover, in Europe the burnt area increases annually, a trend likely to continue as the World Health Organization identified fire as a growing threat for the coming years because of global warming. Despite the dramatic rise of forest fires all around the world, currently, 11 hectares per second burn in the whole world, it is noticeable that forest managers have always tried to increase their efforts towards fighting forest fires, but in many cases the main problem comes from determining the current state of the fire front. This valuable information can be described by the geometrical characteristics of the flame (position, height and tilt angle) and rate of spread.

Some authors have measured these physical and geometrical characteristics of the flame using thermal and/or image processing techniques [1-6]. In addition, it was shown that these parameters depend on wind velocity, fuel moisture content and slope of ground surface $[7,8]$. Studies of the effects of these factors are carried out in laboratory conditions [9-19] or under controlled fires in real vegetation beds [20-22]. One of the largest database found in the literature about flame characteristics and rate of spread is presented by Mendes-Lopes et al. [16]. Their experiments were performed in a dedicated burning tray, where wind velocity, fuel moisture content and slope were varied to study fire propagation in beds of Pinus pinaster needles. However, the main drawback is that their experimental tests are costly and they do not cover the entire range of test conditions. Therefore, it is extremely difficult and sometimes impossible to predict the flame characteristics and the rate of spread for new cases 
which are not included in the database. Thus, having a tool for generalization of new cases is of practical interest for saving time and money.

Other literature sources have focused on the determination of these flame characteristics using physics-based computational fire models [23-30]. These valuable approaches are useful to improve the understanding of the mechanisms that are responsible for fire behaviour. On the other hand they need a large amount of computational resources [31] and several input parameters (e.g. heat transfer coefficient, characteristics of thermal degradation, turbulent kinetic energy and its dissipation rate) which are hard to measure or not available in many cases. It is also not possible to integrate observed data directly at desired locations to improve model results. Simplified or reduced propagation models have therefore been developed [32, 33]. These models generally require input parameters, which depend on the fire itself, such as flame length and tilt angle [31]. Empirical models based on experimental results have been also developped to create relationships between variations in fire behaviour factors and characteristics [34]. For the ability to simulate quickly and accurately, the geometrical characteristics of the flame and rate of spread are of crucial importance in fire forecasting operations.

Here an approach is proposed based on artificial neural networks (ANNs) for simulating the rate of spread $(R O S)$, flame height $\left(H_{f}\right)$ and flame angle $\left(\alpha_{f}\right)$. The ANN provides a quick and flexible approach for data integration and model development. Over the last two decades, ANNs have been successfully used by many researchers for a wide range of engineering applications [35]. An ANN is based on the substitution of the complex simulation model by an approximation of the input-output relationship. The ANN has the advantage over regression that the form of the model needs not to be pre-determined [36]. In addition, the ANN can theoretically approximate any function to any level of accuracy, which is very interesting when the governing physical mechanisms are non-linear like in forest fire 
propagation behaviour research. The experimental results found in the literature [16] are used to construct, to optimize and to validate the ANN model. The performance of the proposed ANN model is compared with a multilinear regression approximation method.

\section{Construction of ANN models}

\subsection{Artificial neural networks}

In this study, an artificial neural network (ANN) was used to predict the flame height $\left(H_{f}\right)$, flame angle $\left(\alpha_{f}\right)$ and rate of spread $(R O S)$ of a bed of Pinus pinaster needles. An ANN is a powerful mathematical tool used to model non-linear relationships between inputs and outputs without any a priori knowledge of the model. ANN models learn the relationship between the input and the output parameters as a result of training with previously recorded data.

\subsection{Construction of the database}

The database was built using experimental data which were collected from the literature [16] with input parameters: slope $(S)$, fuel moisture content $(F M C)$ and wind velocity $(W)$ varying in a range of representative values: $-15^{\circ},-10^{\circ},-5^{\circ}, 0^{\circ}, 5^{\circ}, 10^{\circ}$ and $15^{\circ}$ for $S ;(10 \pm 1) \%$ and $(18 \pm 1) \%$ for $F M C$ and $-3,-2,-1,0,1,2$ and $3 \mathrm{~m} / \mathrm{s}$ for $W$. The fuel bed used in the experiments [16] is composed of Pinus pinaster needles with a depth of $4 \mathrm{~cm}$ and a load of $0.5 \mathrm{~kg} / \mathrm{m}^{2}$. It should be noted that the negative values of $W$ refer to backing fires and the negative value for $S$ corresponds to down-slope orientation. More information about the experimental procedure can be found in Mendes-Lopes et al. [16]. Totally, the database contains an appreciable size of 64 experimental test points.

The present database was subdivided in three subsets. A first subset (30 experimental tests) was used to train the network. A second one (16 experimental tests) was used to test the 
ANN models to determine when to stop the training stage. The third subset (18 experimental tests) was used to validate the performance of the selected model on unseen cases.

Each input or output parameter was normalized relative to its minimum and maximum values observed in the data (according to Eq. (1)) to make the training procedure more efficient.

$$
X_{\text {norm }}=\frac{\left(X-X_{\min }\right)}{\left(X_{\max }-X_{\min }\right)}
$$

where $X$ is an arbitrary parameter, $X_{\text {norm }}$ is the normalized value, and $X_{\max }$ and $X_{\min }$ are the maximum and minimum values of $X$ respectively.

\subsection{Architecture and learning process of ANN models}

An artificial neural network model is composed of interconnected groups of artificial neurons or nodes. The most frequently utilized network is the multilayer backpropagation

neural network (BPNN) which is used in the present study. The BPNN structure consists of three layers, an input layer which receives data; an output layer which sends computed information; and one or more hidden layers to link the input and output layer. All the neurons (nodes) in a layer are connected with all the neurons of the previous and the next layer. In general, the number of the nodes in the input and output layer are determined by the nature of the problem. The architecture of a typical 3-layer backpropagation neural network is shown in Fig. 1. 


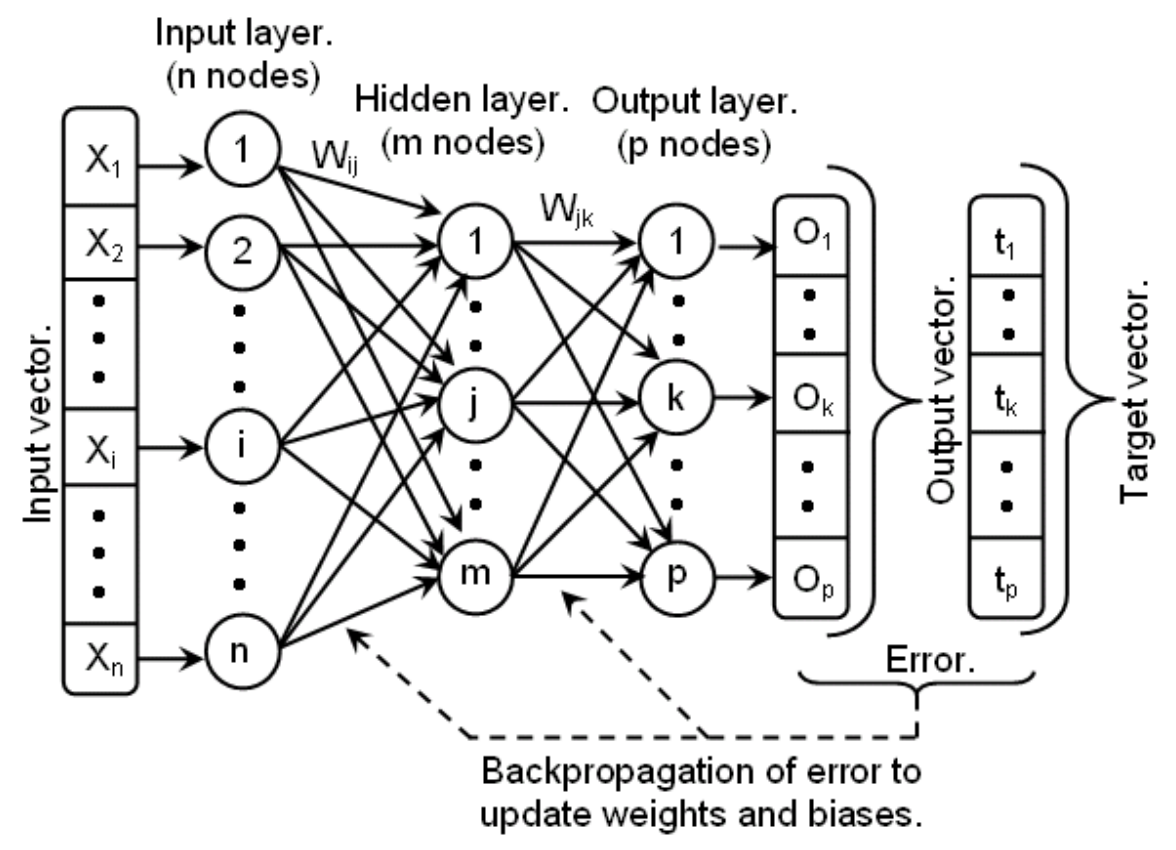

Fig. 1 Architecture of a typical multilayer BPNN.

Mathematically, a 3-layer BPNN with $n, m$, and $p$ the number of input, hidden and output neurons respectively, can be formulated as follows:

$$
O_{k}=f\left(b_{k}+\sum_{j=1}^{m} f\left(b_{j}+\sum_{i=1}^{n} W_{i j} X_{i}\right) \times W_{j k}\right)
$$

where $X_{i}$ are the input values of the network and $O_{k}$ are the output values; $b_{j}$, the hidden unit biases; $b_{k}$, output nodes biases; $W_{i j}$, the connection weights between the input layer and the hidden layer; $W_{j k}$, the connection weights between the hidden layer and the output layer and $f$ is a transfer function. The sigmoid transfer function (Eq. (3)) is represented as:

$$
f(x)=\frac{1}{1+e^{-x}}
$$

Where $x$ is the excitation. 
The learning process of the BPNN is based on a series of connection weight adjustments in order to minimize the gap (global error) between the outputs of the BPNN and the target values [37]. Initially, all biases and connection weights are initialized to random values in the range of $[-1,+1]$. Inputs are first propagated forward through each layer of the ANN. Errors between outputs and target values are then propagated backwards and the connection weights are modified according to a specific learning algorithm (delta rule) to reduce the overall error. This process (forward-backward) is repeated until predicted outputs and target answers coincide within a given tolerance [38].

The most common convergence criterion is the average squared error (ASE) defined as:

$$
A S E=\frac{1}{p} \times \frac{1}{s} \times \sum_{q=1}^{s} \sum_{k=1}^{p}\left(t_{q k}-O_{q k}\right)^{2}
$$

where $t_{q k}$ and $O_{q k}$ are the target and predicted value of the output node k for the pattern $q$ respectively, $p$ is the number of output nodes, and $s$ is the number of patterns. It should be noted that any level of agreement between predicted and target vectors can be achieved by providing a sufficient number of training cycles. Such an overtraining is, however, detrimental to the capacity of the network to generalize from unseen data (a network that can accurately predict the output of the testing patterns is said to have generalized). It is thus preferable to calculate the ASE both on training and testing patterns during training cycles for optimum convergence: this process is called cross-validation (Fig. 2). 


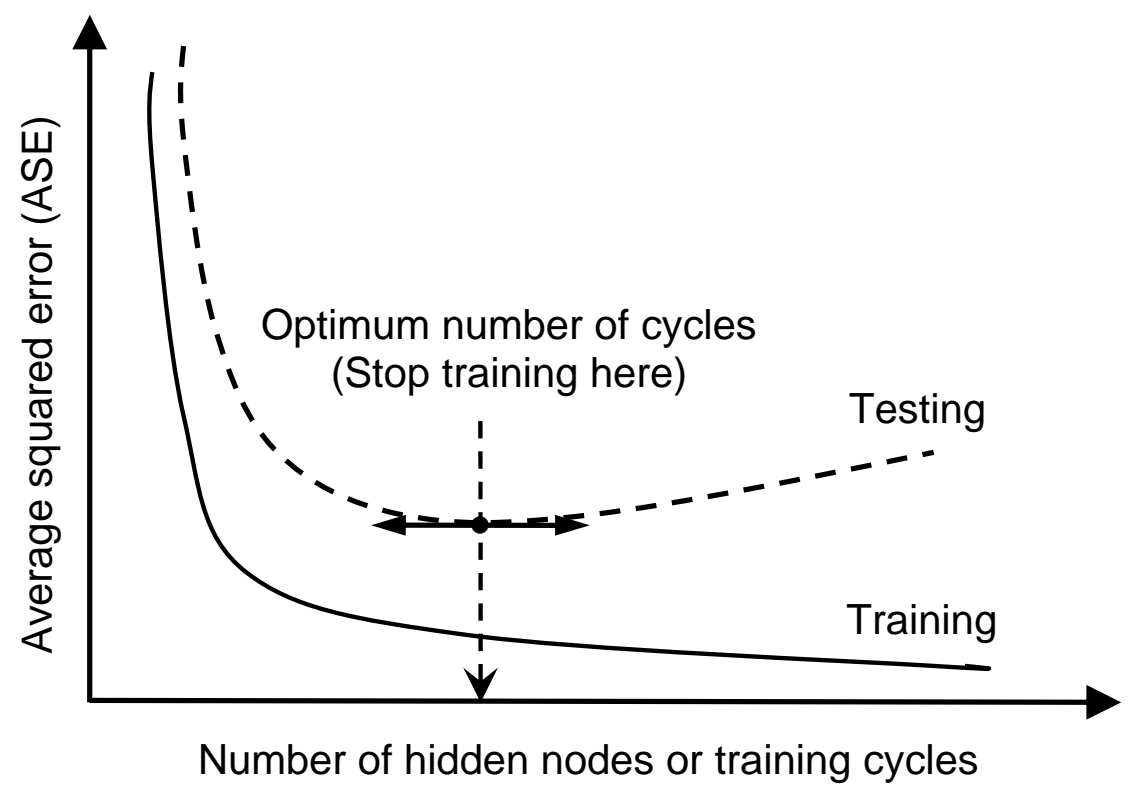

Fig. 2 Convergence criterion and optimum network architecture.

\section{Results and Discussion}

\subsection{Optimum artificial neural network architecture}

The determination of the ANN architecture constitutes one of the major tasks in the use of the ANN. The overall performance of an ANN is dependent on the number of hidden layers and hidden nodes. In the usual case of a 3-layer BPNN, the optimum number of hidden nodes can be determined by cross-validation in the same way as for the optimum number of training cycles (Fig. 2).

In the present article, a neural network relating inputs $\left\{X_{1}, X_{2}, \ldots, X_{n}\right\}$ to outputs $\left\{O_{1}, O_{2}\right.$, $\left.\ldots, O_{p}\right\}$ and containing one hidden layer with $\mathrm{m}$ hidden nodes is noted as:

$$
\left\{O_{1}, O_{2}, \ldots, O_{p}\right\}=\mathrm{ANN}_{\mathrm{n} \mathrm{m}}\left\{X_{1}, X_{2}, \ldots, X_{n}\right\}
$$

In our case, $R O S, H_{f}$ and $\alpha_{f}$ are sought as a function of $S, F M C$ and $W$. So, it is possible to compute $R O S, H f$ and $\alpha_{f}$ by using a BPNN model with three nodes in the output layer (Eq. $(6))$. 
As can be observed in Fig. 3 the optimal value of ASE was calculated while using 5 nodes in the hidden layer of the model.

$$
\left\{R O S, H_{f}, \alpha_{f}\right\}=\mathrm{ANN}_{3-5-3}\{S, F M C, W\}
$$

The ASE values for the training, testing and validation phases for the optimal artificial neural network model $\left(\mathrm{ANN}_{3-5-3}\right)$ are 1.37E-3, 2.39E-3 and 6.28E-3 respectively.

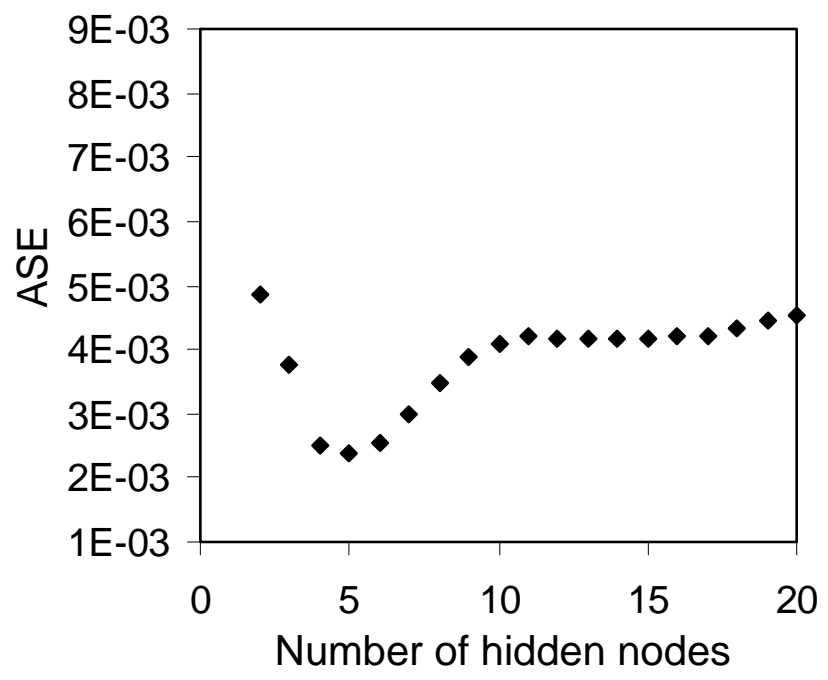

Fig. 3 Average squared error (ASE) variations with the number of hidden nodes for the testing data subset.

\subsection{Discussion of the performance of the models}

The performance of the ANN model is evaluated by comparing target $\left(Y_{i}\right)$ and predicted $\left(\hat{Y}_{i}\right)$ values. Fig. 4, Fig. 5 and Fig. 6 show the comparison between the BPNN predicted values and the target values for $R O S, H_{f}$ and $\alpha_{f}$ on training, testing and validation data. In the same graphs the best fit through the origin is also plotted and the coefficient of determination $R^{2}$ for this line is computed. $R^{2}$ coefficients close to unity indicate a high degree of linearity between predicted and target values. Associated with a best fit slope close to unity, it indicates a high model prediction accuracy. 
A basis of comparison for BPNN performance is usually sought in multiple linear regression [39], a more ubiquitous prediction tool in fires propagating research. Least square parameter fitting for three different linear models (models 2 through 4) expressing $R O S, H_{f}$ and $\alpha_{f}$ as a function of $S, F M C$ and $W$ (Eq. (7-9)) are performed on the same training database subset as for BPNN model.

$$
\begin{array}{ll}
R O S=0.011 \times S+0.0605 \times F M C+0.5275 \times W & (\text { Model 2) } \\
H_{f}=0.3938 \times S+1.5661 \times F M C+4.9664 \times W & (\text { Model 3) } \\
\alpha_{f}=-0.9399 \times S+6.8 \times F M C-22.3092 \times W & (\text { Model 4) }
\end{array}
$$

These models were tested to predict the never-seen data from the BPNN validation database subset. The lowest $R^{2}$ value is obtained for multiple linear regression models. It is also noted that the trend line deviates somewhat from the 1:1 line in case of models 2 through 4. The coefficients of determination for models 1 through 4 for all training, testing and validation phases are given in Table 1. The multiple linear regression models seem to be less efficient than model 1, the ANN model, for predicting the variations of $R O S, H_{f}$ and $\alpha_{f}$. This result is expected: the physical phenomena captured in the database are complex and nonlinear. In an ANN non-linearity is accounted for by the use of transfer functions (Eq. (3)), while complexity can be controlled by varying the number of hidden nodes. In the present case, the artificial neural network provides good and realistic predictions. 

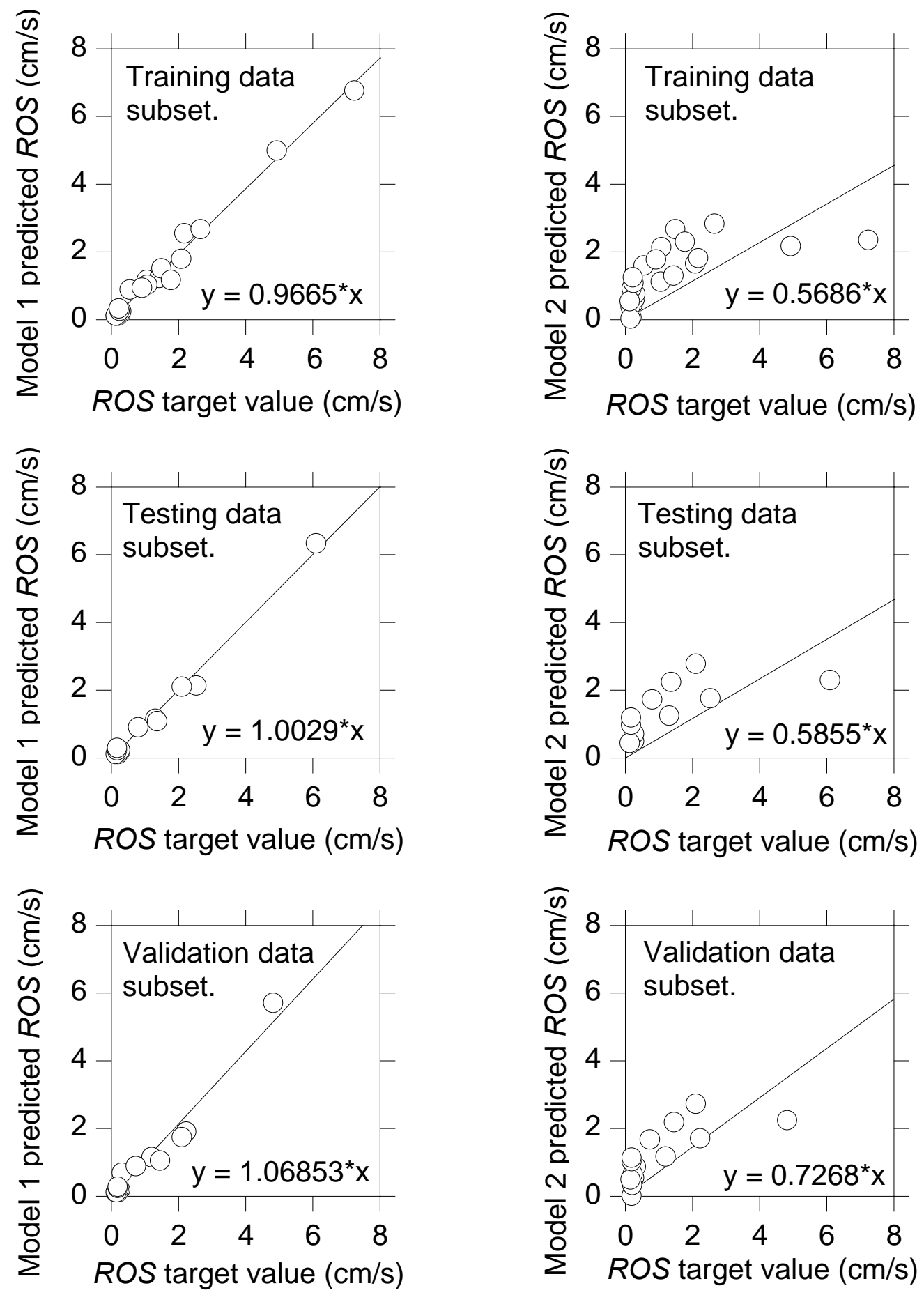

Fig. 4 Comparison between target and predicted values for ROS using BPNN (model 1) and multi-linear regression (model 2) for all data subsets. 

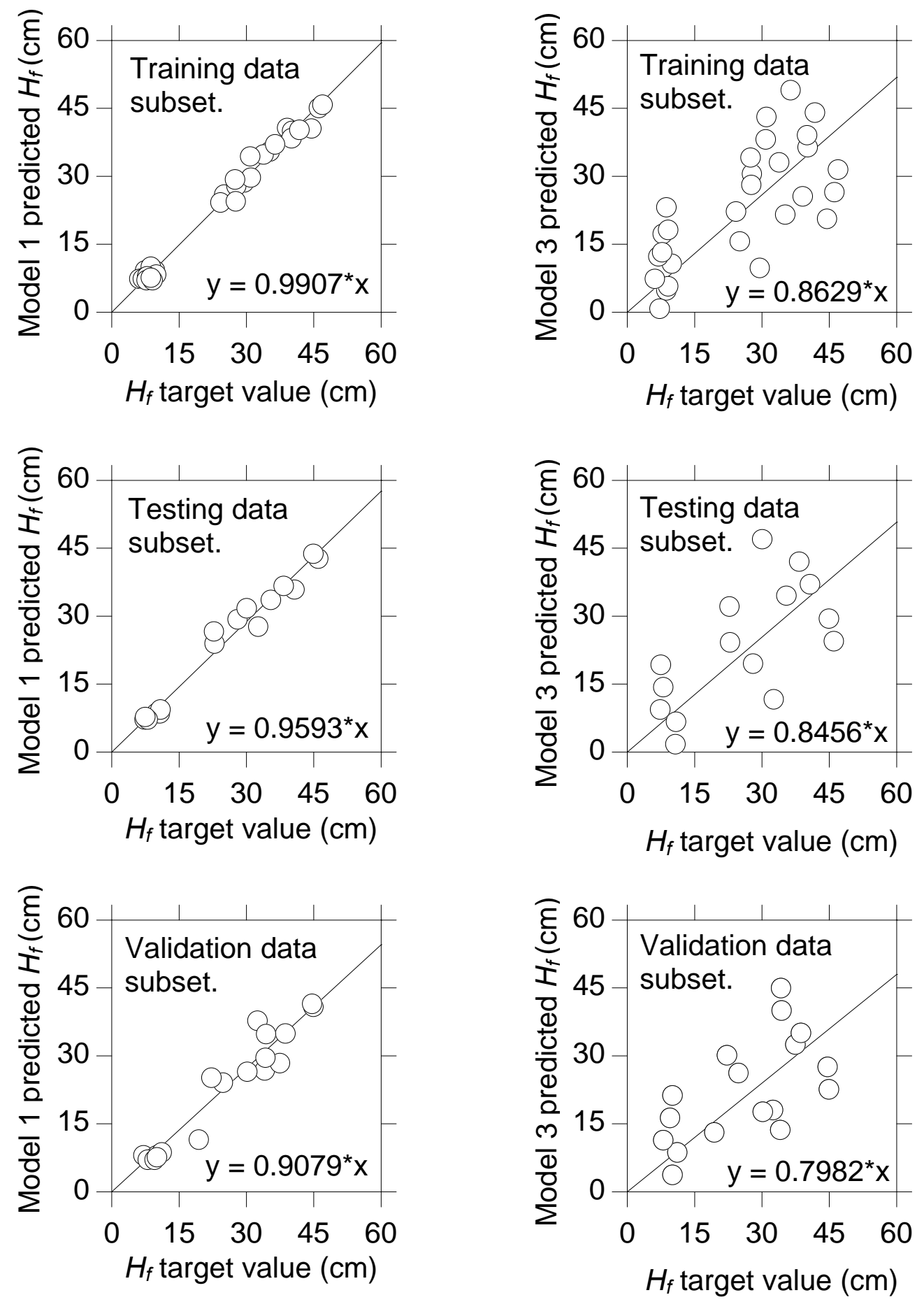

Fig. 5 Comparison between target and predicted values for $H_{f}$ using BPNN (model 1) and multi-linear regression (model 3) for all data subsets. 

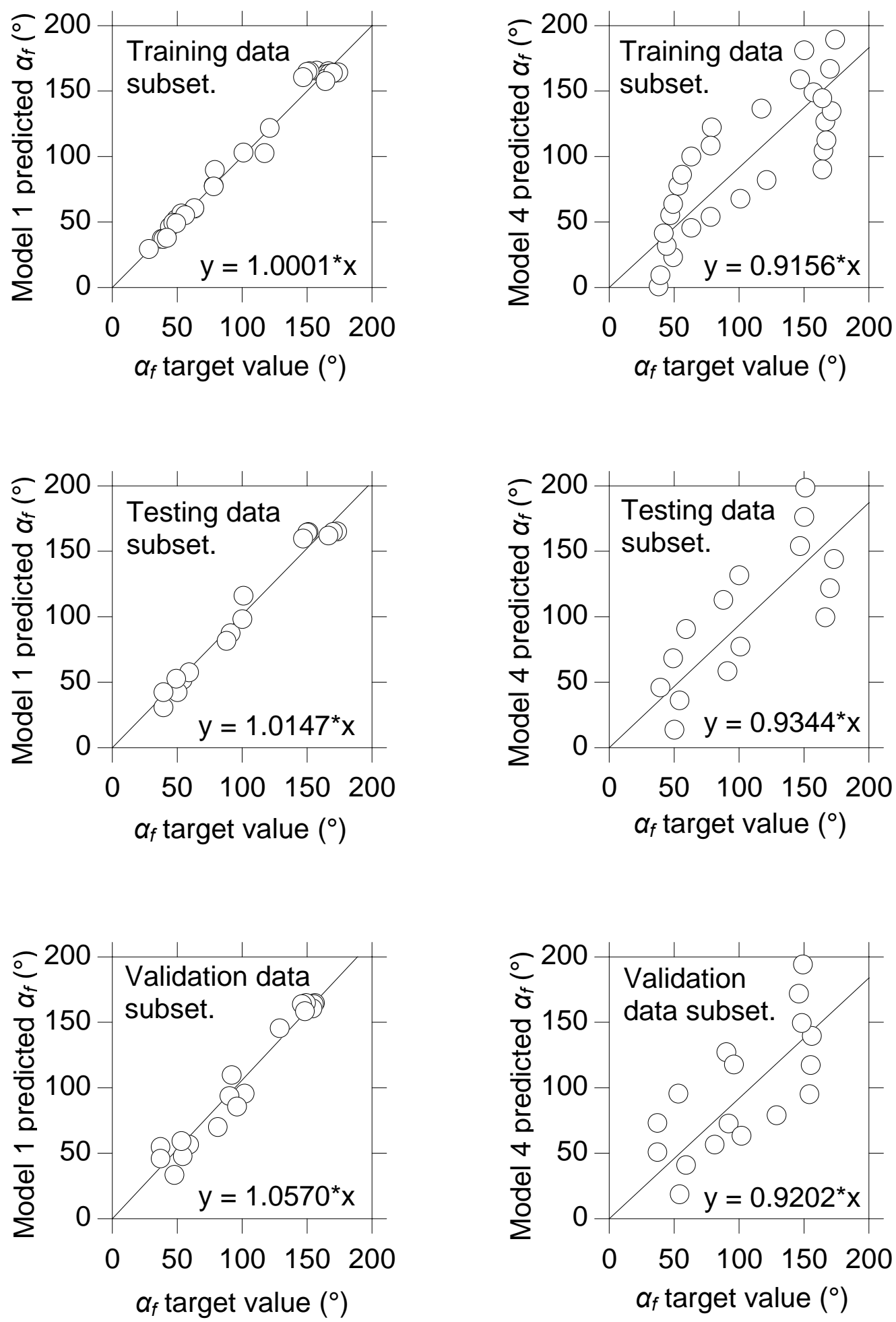

Fig. 6 Comparison between target and predicted values for $\alpha_{f}$ using BPNN (model 1) and multi-linear regression (model 4) for all data subsets. 
Table 1: $R^{2}$ values for the ANN model and the three multiple linear regression models on all datasets.

\begin{tabular}{|c|c|c|c|c|c|c|}
\hline \multirow{3}{*}{$R^{2}$} & \multicolumn{3}{|c|}{ Neural network } & \multicolumn{3}{|c|}{ Multiple linear regression } \\
\hline & \multicolumn{3}{|l|}{ Model 1} & \multirow{2}{*}{$\begin{array}{l}\text { Model } 2 \\
\text { ROS }\end{array}$} & \multirow{2}{*}{$\begin{array}{l}\text { Model } 3 \\
\mathrm{H}_{\mathrm{f}}\end{array}$} & \multirow{2}{*}{$\begin{array}{l}\text { Model } 4 \\
\alpha_{\mathrm{f}}\end{array}$} \\
\hline & ROS & $\mathrm{H}_{\mathrm{f}}$ & $\alpha_{\mathrm{f}}$ & & & \\
\hline Training phase & 0.9869 & 0.9881 & 0.9845 & 0.4030 & 0.5513 & 0.6782 \\
\hline Testing phase & 0.9913 & 0.9738 & 0.9758 & 0.4119 & 0.4744 & 0.6446 \\
\hline Validation phase & 0.9626 & 0.9261 & 0.9593 & 0.4826 & 0.4464 & 0.5555 \\
\hline
\end{tabular}

\subsection{Comparison to models and experimental data from literature}

A comparison is made with models from literature describing flame propagation in fuel beds of Pinus needles [40-42]. The model of Anderson and Rothermel [40] is a semiempirical one where rates of spread are predicted as a function of fuel particle size, fuel bed compactness with fuel moisture content and wind velocity. The model of Porterie et al. [41] is a physical one, e.g., a detailed description of the heat and mass transfer mechanisms, combustion and turbulence is given. As this model is computationally intensive, the approach of Porterie et al. [41] is limited up to now to line fires for which a $2 \mathrm{D}$ approximation in a plane defined by the direction of propagation is applied. The model of Morandini et al. [42] is also a physical model. This model incorporates a reaction-diffusion equation for the thermal balance and a simplified one-dimensional formulation represents the flow in the fuel layer.

The predicted rates of spread and some experimental data of Mendes-Lopes et al. [16] are provided in Fig. 7 for a horizontal spread $(S=0), F M C=10 \%$ and wind velocity ranging from 0 to $3 \mathrm{~m} / \mathrm{s}$. These experimental values are selected from the third subset of 18 experimental tests which are not used to calibrate the developed model as described in subsection 2.2. Fig. 7 gives also two experimental sets of data from literature $[8,43]$ and predicted rates of spread 
obtained by the three models described above. It is clear regarding this figure that there is a discrepancy between these three experimental data. Indeed, experimental values of Boboulos and Purvis [8] are obtained for a Pinus pinaster fuel bed with a load three times higher than the one of Mendes-Lopes et al. [16]. In addition, experiments of Fernandes et al. [43] are performed at field scale where the control of wind speed, fuel load and depth are very difficult compared to laboratory experiments. The fire behaviour predicted by the present model (BPNN) is in good agreement in comparison to the three models cited above. The present model and these literature models give predicted rates of spread close to those measured by Mendes-Lopes et al. [16] compared to the other experimental data. The models of Anderson and Rothermel [40] and Porterie et al. [41] underestimate the experimental rate of spread [16] for the highest wind velocity $(\mathrm{W}=3 \mathrm{~m} / \mathrm{s})$. This latter gives also predicted rate of spread slightly lower than the experimental value for a wind speed of $2 \mathrm{~m} / \mathrm{s}$. The model of Anderson and Rothermel [40] may be very efficient for fuel and environmental conditions comparable to those of the test-fires used to tune them but the lack of a real physical description make it not applicable in other situations. Although the structure of the model of Porterie et al. [41] is very sound, conversely it possesses a great set of submodels (thermal degradation of fuels, heat transfer in porous medium, gaseous kinetics for combustion, drag forces) used to close it. Those submodels need improvement to allow better predictions [27]. In the contrary of the models of Porterie et al. [41] and Morandini et al. [42], the developed model is not based on physical modeling. Nevertheless, the last model and the developed one match well the experimental data subset of Mendes-Lopes et al. [16] which are not handled to calibrate the proposed model. It should be noted that the flame height is an input parameter in the physical approach of Morandini et al. [42] and it is computationally intensive. 


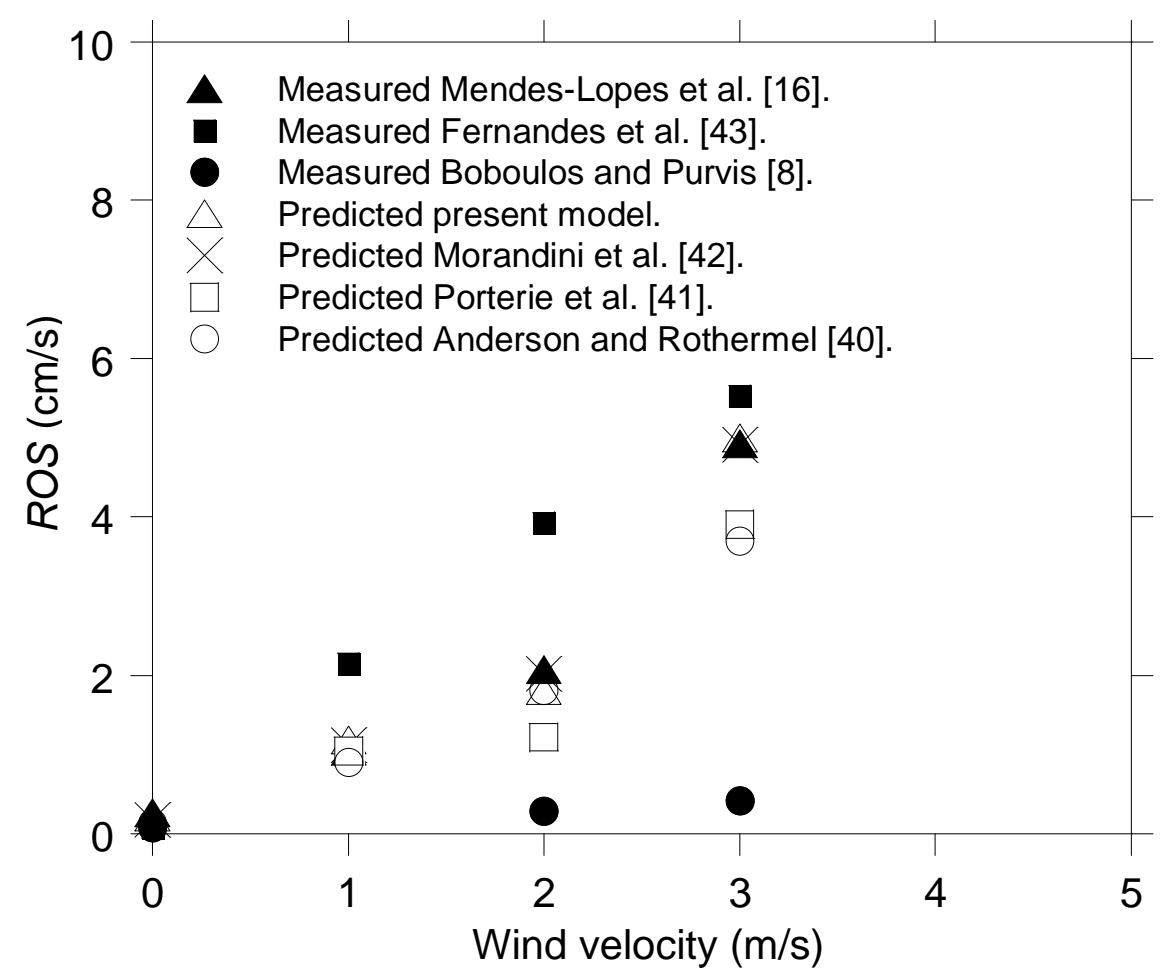

Fig. 7 Comparison between some predicted models and experimental data $[8,16,43]$ for windblown fire spread across a fuel bed of Pinus pinaster needles $(F M C=10 \%$ and $S=0)$.

\subsection{Application of the BPNN model to predict fire behaviour}

An application of ANN is now proposed in the following part. Considering a constant slope $(S)$ of $7 \%$, it is now possible to simulate the variation of $R O S, H_{f}$ and $\alpha_{f}$ within the range of $[-2.5 \mathrm{~m} / \mathrm{s},+2.5 \mathrm{~m} / \mathrm{s}]$. The evolution of the rate of spread $(R O S)$ using the BPNN as a function of fuel moisture content $(F M C)$ yields a decrease in $R O S$ when the fuel moisture content increases (Fig. 8). It can also be observed also that the predicted ROS increases steeply with wind velocity for wind-driven fires $(W>0)$ but does not depend on wind speed for backing fire spread rates $(W<0)$. The results obtained agree with the observations reported in literature [16]. It is thus very important to note that the BPNN approach is able to reproduce physical variations. 


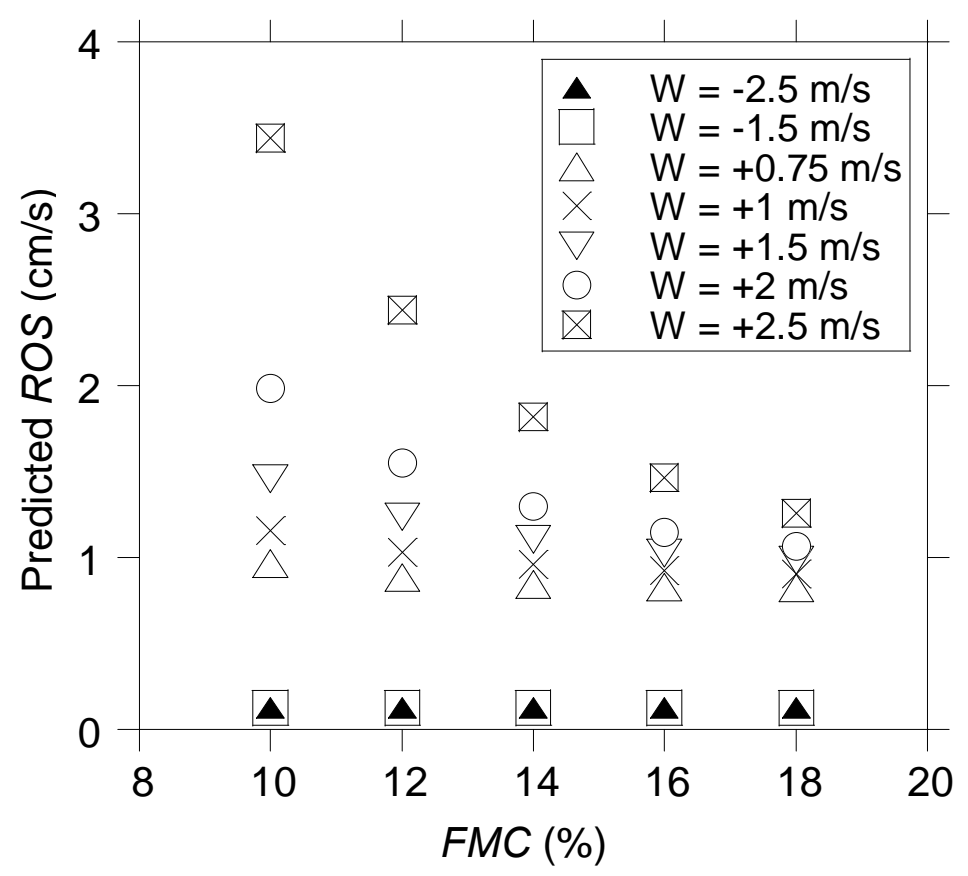

Fig. $8 \mathrm{BPNN}$ model predicted $R O S$ variations with fuel moisture content for $S=7 \%$.

The BPNN predicted $H_{f}$ values as a function of fuel moisture content $(F M C)$ and wind velocity (for $S=7 \%$ ) is shown in Fig. 9. It can be seen that the predicted $H_{f}$ values decrease with fuel moisture content (for a constant wind velocity). Moreover, it can be concluded physically, that the wind velocity and the fuel moisture content play an important role in the determination of the flame height.

The BPNN predicted $\alpha_{f}$ values as a function of fuel moisture content $(F M C)$ and the wind velocity (for $S=7 \%$ ) is shown in Fig. 10. It can be seen that the predicted $\alpha_{f}$ values increase when the fuel moisture content increases (for a constant wind velocity). Moreover, it can be concluded also that the wind velocity and the fuel moisture content have almost no effect on $\alpha_{f}$ for the backing fire spread rate $(W<0)$. 


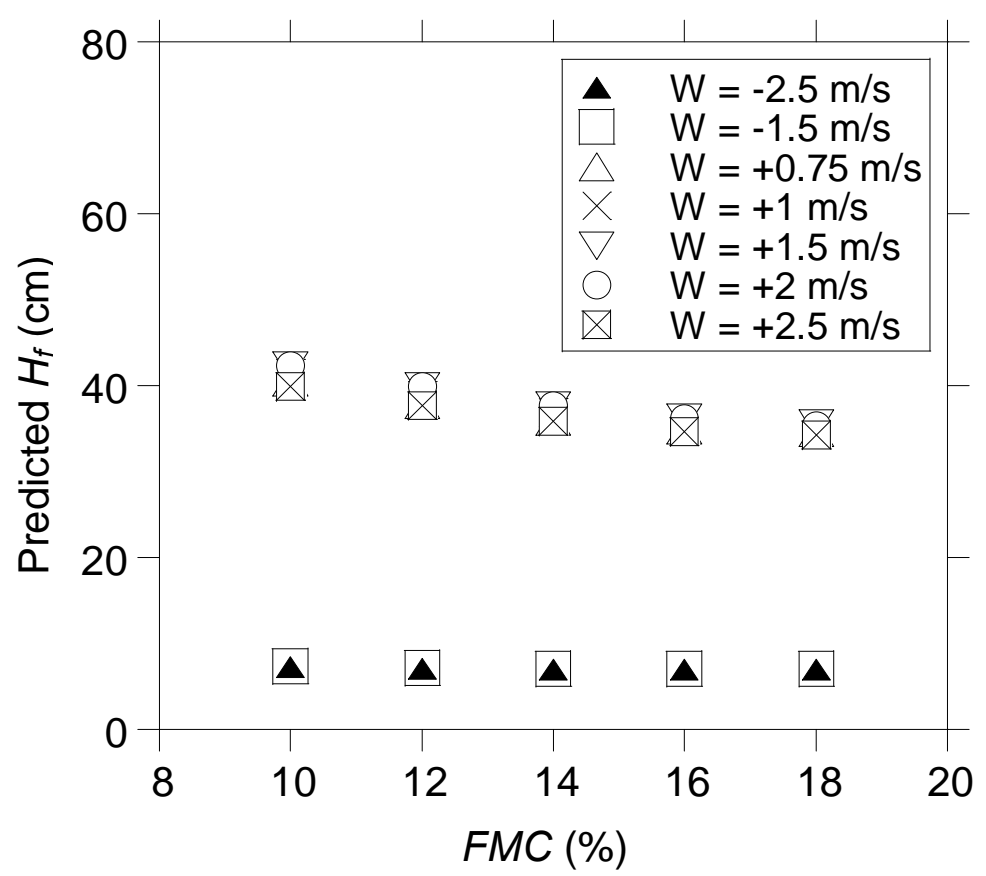

Fig. 9 BPNN model predicted $H_{f}$ variations with fuel moisture content for $\mathrm{S}=7 \%$.

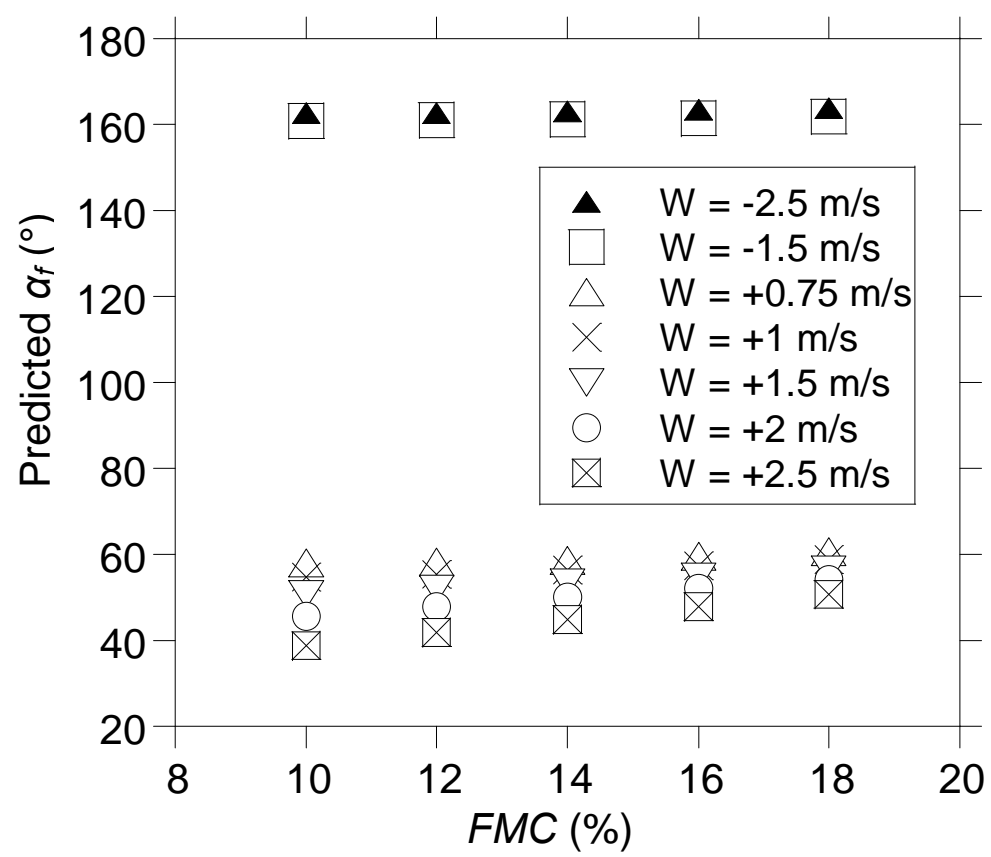

Fig. $10 \mathrm{BPNN}$ predicted $\alpha_{f}$ variations with fuel moisture content for $\mathrm{S}=7 \%$.

\section{Conclusions}

An artificial neural network tool was used to simulate the rate of spread (ROS), flame height $\left(H_{f}\right)$ and flame angle $\left(\alpha_{f}\right)$ in fires propagating in a bed of Pinus pinaster needles. Based 
on experimental data found in literature, the optimum architecture of the artificial neural network was trained and validated, in order to generalise the prediction of $R O S, H_{f}$ and $\alpha_{f}$ under different configurations not included in the database. The validation (using a set of experimental data which are not handled to calibrate the proposed model) showed good performance of this ANN model for the prediction of the flame characteristics $\left(H_{f}\right.$ and $\left.\alpha_{f}\right)$ and rate of spread $(R O S)$ in fires propagating in a bed of Pinus pinaster needles $\left(\mathrm{R}^{2}>0.92\right)$. In addition, this model has been compared to three literature models ( 2 physical models and 1 semi-empirical model) and the obtained results are very close. All these models (even the proposed one) have been confronted to two other sets of experimental data from literature works and the observed discrepancy has been discussed. The ANN was applied to an application, where it proved powerful and effective in the evaluation of the $R O S, H_{f}$ and $\alpha_{f}$ by using data not included in the database.

\section{REFERENCES}

[1] Zhou X, Weise D and Mahalingam S. Experimental measurements and numerical modeling of marginal burning in live chaparral fuel beds. P Combust Inst 2005; 30 : 2287-2294.

[2] Pastor E, Àgueda A, Andrade-Cetto J, Muñoz M, Pérez Y and Planas E. Computing the rate of spread of linear flame fronts by thermal image processing. Fire Safety $\mathbf{J}$ 2006; 41: 569-579.

[3] Ononye A.E, Vodacek A and Saber E. Automated extraction of fire line parameters from multispectral infrared images. Remote Sens Environ 2007; 108: 179-188. 
[4] Chetehouna K, Séro-Guillaume O, Sochet I, Degiovanni A. On the experimental determination of flame front positions and of propagation parameters for a fire. Int $\mathrm{J}$ Thermal Sci 2008; $47:$ 1148-1157.

[5] Martinez-de Dios J.R, Arrue B.C, Ollero A, Merino L and Gómez-Rodríguez F. Computer vision techniques for forest fire perception. Image Vision Comput 2008; $26: 550-562$.

[6] Rudz S, Chetehouna $\mathrm{K}$ and Séro-Guillaume O. Metrological Tool for the Characterization of Flame Fronts Based on the Coupling of a Heat Flux Approach with Image Processing Data. Fire Technol 2011; 47: 491-505.

[7] Viegas D. Slope and wind effect on fire propagation. Int J Wildland Fire 2004; 13; $143-156$.

[8] Boboulos $\mathrm{M}$ and Purvis M.R.I. Wind and slope effects on ROS during the fire propagation in East-Mediterranean pine forest litter. Fire Safety J 2009; 44: 764-769.

[9] Anderson H.E. Fire spread and flame shape. Fire Technol 1968; 4: 51-58.

[10] Nelson R.M and Adkins C.W. Flame characteristics of wind-driven surface fires. Can J Forest Res 1986; 18: 391-403.

[11] Bradstock R and Gill A. Fire in semi arid, mallee shrublands-size of flame from discrete fuel arrays and their role in spread rate. Int J Wildland Fire 1993; 3: 3-12.

[12] Dupuy J.L. Slope and fuel load effects on fire behavior: laboratory experiments in pine needle fuel beds. Int J Wildland Fire 1995; 5: 153-164. 
[13] Morandini F, Santoni P.A and Balbi J.H. Fire front width effects on fire spread across a laboratory scale sloping fuel bed. Combust Sci Technol 2001; 166: 67-90.

[14] Santoni P.A, Marcelli T and Leoni E. Measurement of fluctuating temperatures in a continuous flame spreading across a fuel bed using a double thermocouple probe. Combust Flame 2002; 131: 47-58.

[15] Dupuy J.L, Marechal J and Morvan D. Fires from a cylindrical forest fuel burner: combustion dynamics and flame properties. Combust Flame 2003; 135: 65-76.

[16] Mendes-Lopes J.M.C, Ventura J.M.P and Amaral J.M.P. Flame characteristics, temperature-time curves and rate of spread in fires propagating in a bed of pinus pinaster needles. Int J Wildland Fire 2003; 12: 67-84.

[17] Bartoli P, Simeoni A, Biteau H, Torero J.L. and Santoni P.A. Determination of the main parameters influencing forest fuel combustion dynamics. Fire Safety J 2011; 46: 27-33.

[18] Fuentes A and Consalvi J.L. Experimental study of the burning rate of small-scale forest fuel layers. Int J Therm Sci 2013; 74: 119-125.

[19] Morandini F, Perez-Ramirez Y, Tihay V, Santoni P.A and Barboni T. Radiant, convective and heat release characterization of vegetation fire. Int J Therm Sci 2013; 70: 83-91.

[20] Marsdden-Smedley J.B and Catchpole W.R. Fire behaviour modelling in Tasmanian buttongrass moorlands. II fire behaviour. Int J Wildland Fire 1995; 5: 215-228. 
[21] Burrows N.D. Fire behavior in jarrah forest fuels, Field experiments. CALMscience 1999; 3: 57-84.

[22] Butler B.W, Cohen J, Lathan D.J, Schuette R.D, Sopko P, Shannon K.S, Jimenez D and Bradshawl L.S. Measurement of radiant emissive power and temperatures in crown fires. Can J Forest Res 2004; 34: 1577-1587.

[23] Morvan D and Dupuy J.L. Modeling of fire spread through a forest fuel bed using a multiphase formulation. Combust Flame 2001; 127: 1981-1994.

[24] Morvan D and Larini M. Modeling of one dimensional fire spread in pine needles flame with opposing air flow. Combust Sci Technol 2001; 164: 37-64.

[25] Simeoni A, Santoni P.A, Larini $M$ and Balbi J.H. Proposal for theoretical improvement of semi-physical forest fire spread models thanks to a multiphase approach: application to a flame fire spread model across a fuel bed. Combust Sci Technol 2001; 162: 59-83.

[26] Simeoni A, Santoni P.A, Larini $\mathrm{M}$ and Balbi J.H. Reduction of a multiphase formulation to include a simplified flow in a semi-physical model of fire spread across a fuel bed. Int J Therm Sci 2003; 42: 95-105.

[27] Balbi J.H, Rossi J.L, Marcelli T and Santoni P.A. A 3D Physical Real-Time Model of Surface Fires Across Fuel Beds. Combust Sci Technol 2007; 179: 2511-2537.

[28] Morvan D, Méradji S and Accary G. Physical modelling of fire spread in Grasslands. Fire Safety J 2009; 44: 50-61. 
[29] Balbi J.H, Rossi J.L, Marcelli T and Chatelon F.J. Physical Modeling of Surface fire under Nonparallel Wind and Slope Conditions. Combust Sci Technol 2010; 182: 922939.

[30] Menage D, Chetehouna K and Mell W. Numerical simulations of fire spread in a Pinus pinaster needles fuel bed. J Physics: Conference Series 2012; 395: 012011.

[31] Nmira F, Consalvi J.L, Boulet P and Porterie B. Numerical study of wind effects on the characteristics of flames from non-propagation vegetation fires. Fire Safety J 2010; 45: 129-141.

[32] Margerit J and Séro-Guillaume O. Modelling forest fires. Part II: reduction of twodimensional models and simulation of propagation. Int J Heat Mass Tran 2002; 45: $1723-1737$.

[33] Koo E, Pagni P, Woycheese J, Stephen S, weise D and Huff J. A simple model for forest fire spread rate. Fire Safety Science-Proceedings of the sixth International Symposium 2005: 851-862.

[34] Pastor E, Zárate L, Planas E and Arnaldos J. Mathematical models and calculation systems for the study of wildland fire behaviour. Prog Energ Combust 2003; 29: 139_ 153.

[35] El Tabach E, Lancelot L, Shahrour I and Najjar Y. Use of artificial neural network simulation metamodelling to assess groundwater contamination in a road project. Math Comput Model 2007; 45: 766-776.

[36] Kleijnen J.P.C. Kriging metamodeling in simulation: A review. Eur J Oper Res 2009; 192: 707-716. 
[37] Najjar Y.M, Basheer I.A and Hajmeer M.N. Computational neural networks for predictive microbiology: I. Methodology. Int J Food Microbiol 1997; 34: 27-49.

[38] Duda R.O, Hart P.E and Stork D.G. Pattern Classification, Wiley, NY, USA, 2001, ISBN: 978-0-471-05669-0.

[39] Tabachnick B.G and Fidell L.S. Using multivariate statistics. $6^{\text {th }}$ ed. Boston: Pearson Education, 2013, ISBN-13: 9780205849574.

[40] Anderson H.E and Rothermel R.C. Influence of moisture and wind upon the characteristics of free-burning fires. Int Sym combust 1965; 10: 1009-1019.

[41] Porterie B, Morvan D, Loraud J.C and Larini M. Fire spread through fuel beds: Modelling of the wind-aided fires and induced hydrodynamics. Phys Fluids 2000; 12: $1762-1782$.

[42] Morandini F, Simeoni A, Santoni P.A and Balbi J.H. A model for the spread of fire across a fuel bed incorporating the effects of wind and slope. Combust Sci Technol 2005; 177: 1381-1418.

[43] Fernandes P.M, Botelho H.S and Loureiro C. Models for the sustained ignition and behaviour of low-to-moderately intense fires in maritime pine stands. In: Viegas (Ed.), Forest Fire Research and Wildland Fire Safety, Millpress, Rotterdam 2002; 111. 